\title{
Review Article \\ Mesenchymal Stem Cells and Cancer: Clinical Challenges and Opportunities
}

\author{
Weiping Lin, ${ }^{1,2}$ Linfeng Huang, ${ }^{1}$ Ying Li, ${ }^{1}$ Bin Fang, ${ }^{1}$ Gang Li $\left(\mathbb{D},{ }^{2,3}\right.$ \\ Leilei Chen $\mathbb{D}^{1}{ }^{1}$ and Liangliang $\mathrm{Xu} \mathbb{1}^{1,4}$ \\ ${ }^{1}$ Key Laboratory of Orthopaedics \& Traumatology, The First Affiliated Hospital of Guangzhou University of Chinese Medicine, \\ The First Clinical Medical College, Guangzhou University of Chinese Medicine, Guangzhou, China \\ ${ }^{2}$ Department of Orthopaedics \& Traumatology, Faculty of Medicine, The Chinese University of Hong Kong, \\ Prince of Wales Hospital, Shatin, Hong Kong \\ ${ }^{3}$ Stem Cells and Regenerative Medicine Laboratory, Lui Che Woo Institute of Innovative Medicine, \\ Li Ka Shing Institute of Health Sciences, The Chinese University of Hong Kong, Prince of Wales Hospital, Shatin, Hong Kong \\ ${ }^{4}$ Laboratory of Orthopaedics \& Traumatology, Lingnan Medical Research Center, \\ Guangzhou University of Chinese Medicine, Guangzhou, China
}

Correspondence should be addressed to Gang Li; gangli@cuhk.edu.hk, Leilei Chen; yutian_1010@sina.com, and Liangliang Xu; xull-2016@gzucm.edu.cn

Received 31 December 2018; Revised 19 March 2019; Accepted 10 April 2019; Published 8 May 2019

Academic Editor: Martin Bornhäuser

Copyright (C) 2019 Weiping Lin et al. This is an open access article distributed under the Creative Commons Attribution License, which permits unrestricted use, distribution, and reproduction in any medium, provided the original work is properly cited.

\begin{abstract}
Stem cell-based therapies exhibit profound therapeutic potential for treating various human diseases, including cancer. Among the cell types that can be used for this purpose, mesenchymal stem cells (MSCs) are considered as promising source of stem cells in personalized cell-based therapies. The inherent tumor-tropic property of MSCs can be used to target cancer cells. Although the impacts of MSCs on tumor progression remain elusive, they have been genetically modified or engineered as targeted anticancer agents which could inhibit tumor growth by blocking different processes of tumor. In addition, there are close interactions between MSCs and cancer stem cells (CSCs). MSCs can regulate the growth of CSCs through paracrine mechanisms. This review aims to focus on the current knowledge about MSCs-based tumor therapies, the opportunities and challenges, as well as the prospective of its further clinical implications.
\end{abstract}

\section{Introduction}

MSCs are nonhematopoietic cells that were first discovered from bone marrow and reported approximately 40 years ago by Friedenstein and his coworkers [1,2]. Studies have shown that MSCs exist in a variety of tissues. To date, MSCs have been successfully isolated from various organs including brain, liver, lung, kidney, muscle, thymus, pancreas, skin, bone marrow adipose tissue, fetal tissues, and umbilical cord [3]. Also, MSCs are known as multipotent cells which can differentiate into adipocytes, myocytes, osteocytes, and chondrocytes [4-6]. In 2006, the International Society for Cellular Therapy proposed three minimal criteria to define human MSCs. They must express CD105, CD90, and CD73 and lack expression of CD $45, \mathrm{CD} 34, \mathrm{CD} 14$ or CD11b, CD79 $\alpha$ or CD19, and HLA-DR surface molecules. Additionally, they must adhere to plastic in culture and differentiate into osteocytes, chondrocytes, and adipocytes [7]. In addition, MSCs possess unique immunophenotypic capacity, tissue-repair capacity, and immunoregulatory capacity [8]. Therefore, owing to their relative immune evasiveness and general immune dampening activities, MSCs can be utilized in an allogenic setting and are promising seed cells for cell therapy and tissue engineering [9]. Moreover, various preclinical trials suggest that MSCs show great potential for cancer treatment, although obstacles and risks were described [10].

Studies have shown that MSCs are capable of migrating directionally to specific tissues, which is termed as homing. The tropism property of MSCs into sites of injury and tumor makes them ideal vehicles for targeted tumor therapy, 
although the exact mechanism of MSCs homing is not completely understood. Ongoing preclinical trials suggest that MSCs are suitable targets for cell therapy in a variety of cancers. However, the antitumor effects of MSCs are still controversial. In various types of cancer, some studies have shown proliferative effects, while others demonstrate inhibitory effects of MSCs on tumors [11]. For example, MSCs have tumoricidal effects on liver, lung cancer cell lines, and pancreatic tumors in vitro and in vivo [12-14]. In contrary, it has been shown that MSCs are capable of enhancing progression and metastasis of types of tumor, such as breast cancer and colon cancer [15-18]. In addition, MSCs may exert therapeutic function through an immune evasive mechanism, which will protect MSCs from immune detection and prolong their persistence in vivo [9]. Moreover, the survival of MSCs in the tumor and biodistribution of MSCs should take more attention when designing a trial, which may influence the results of study. For example, although human MSCs were found by staining in the tumors 1 day after IV injection in a mice model, the cells almost were cleared after 1 week [19]. However, even after 11 weeks MSCs were still observed in the tumor, although at very low numbers [19]. In an in vivo study of colon cancer, exogenous MSCs were still able to regulate immune response of the tumor microenvironment even 1 year after the last MSCs injection [20]. In this review, we summarize recent advances of MSCs in the treatment of cancer and insights into potential strategies for cancer therapy.

\section{MSCs and Cancer}

2.1. Discrepancy in Impacts of MSCs on Tumor Progression. Extensive studies have been performed to investigate effects of MSCs on tumor in recent decades. However, this issue is still under debate. Controversial results have been reported. Several studies have shown that MSCs promote tumor progression and metastasis through influencing signaling pathway [18, 39], while other studies suggest that MSCs affect the pathways that can suppress both proliferation and apoptosis $[13,40]$.

Researches have demonstrated that MSCs would be recruited into tumor sites, promoting tumor growth, and angiogenesis through differentiating into cancer-associated myofibroblasts and secretion of proangiogenic cytokines (e.g., interleukin (IL)-6, vascular endothelial growth factor (VEGF), and transforming growth factor- $\beta$ (TGF- $\beta$ ) [21-23]. In the meanwhile, the recruited MSCs also enhanced tumor metastasis via increasing lysyl oxidase [24]. Another tumorpromoting effect of MSCs is attributed to their protection role for breast cancer cells from immune clearance through modulating regulatory $\mathrm{T}$ cells and inhibiting natural killer (NK) cells and cytotoxic T lymphocyte (CTL) functions [25]. Furthermore, MSCs have been found to form a cancer stem cell niche in which tumor cells can preserve the potential to proliferate and sustain the malignant process [41]. Also, increasing evidences suggest that MSCs promote tumor angiogenesis through their potential to differentiate into pericytes or endothelial-like cells as well as by their secretion of trophic factors and cytokines, proangiogenic factors, growth factors, and plasminogen activator [42, 43]. Thus, MSCs promote tumor growth and metastasis through stimulation of angiogenesis, cancer stem cell niche maintenance, and immune protection. Moreover, it has also been showed that MSCs can affect tumor development and progression through miRNAs. In a xenograft tumor model, researchers demonstrated that human umbilical cord MSCs (hUCMSCs) powerfully promote the growth of lung adenocarcinoma (LUAD) cancer cells by transferring miR-410. The findings suggest that modification of hUCMSC-derived extracellular vesicles (hUCMSC-EVs) may be a promising therapeutic option for treatment of tumor [44]. In a mice model, study found that gastric cancer tissue-derived MSCs can significantly promote HGC-27 growth and migration via increasing the expression of miR-221, which may be as a novel biomarker in gastric cancer [45]. The studies supporting MSCs favor tumor growth are summarized in Table 1.

In contrast, it has been shown that the unmodified MSCs have antitumor effects both in vitro and in different animal models of cancer, which is attributed to the factors secreted by MSCs that can suppress the proliferation of glioma, melanoma, hepatoma, and breast cancer cells [4648]. Studies have indicated that MSCs exhibit antiglioma effect through inhibiting vascular growth in glioma cells, which is mediated by the downregulation of platelet-derived growth factor (PDGF)/PDGFR axis [28]. Also, human umbilical cord-derived MSCs (hUC-MSCs) have been shown to inhibit progression of breast cancer by inducing tumor cells death and suppressing angiogenesis [29]. Another study reported that human bone marrow-derived MSCs exhibit the potential to suppress the growth of breast cancer and inhibit lung metastasis by reducing their proliferative ability [30]. Furthermore, MSCs have been shown to have antiangiogenic effect both in vitro and in vivo [49]. MSCs also can inhibit tumor growth in a highly inflammatory and angiogenic Kaposi's sarcoma model [50]. Both in vitro and in vivo studies have shown that MSCs derived from fetal skin can inhibit the growth of human hepatocellular carcinoma (HCC) cells and can reduce cell proliferation, colony formation, and expression of oncogenes [48]. To conclude, MSCs play critical roles in processes of tumor angiogenesis, tumor immune response, and metastasis. The studies reporting MSCs inhibit tumor growth are summarized in Table 2.

\subsection{MSCs, Cancer Stem Cells and Cancer Microenvironment.} Cancer remains as one of the most challenging diseases despite extensive studies have been performed and novel systemic treatment advances during recent decades. In particular, when cancer is diagnosed to have metastasized, treatments are much less successful; while it can often be treated successfully by surgery or local irradiation before it has spread [51]. Therefore, it is necessary and imperative to better understand the biological processes behind the progression of tumor cells towards metastasis.

Cancer cells in primary tumors reside in a complex microenvironment comprising numerous cell types, including endothelial cells of blood vessels, lymphatic circulation, fibroblasts, and various bone marrow-derived cells, such as macrophages and MSCs. It has been well documented 


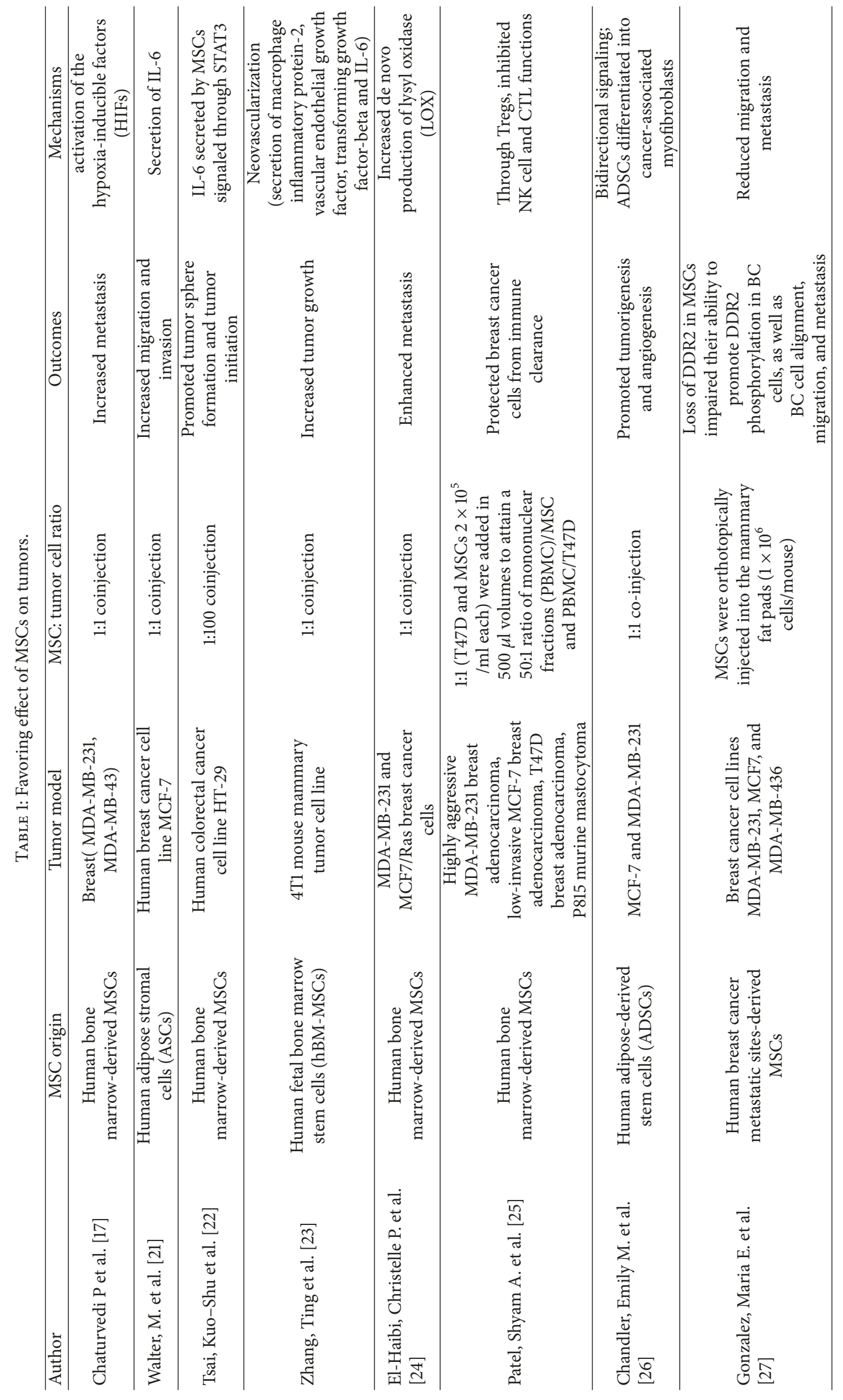




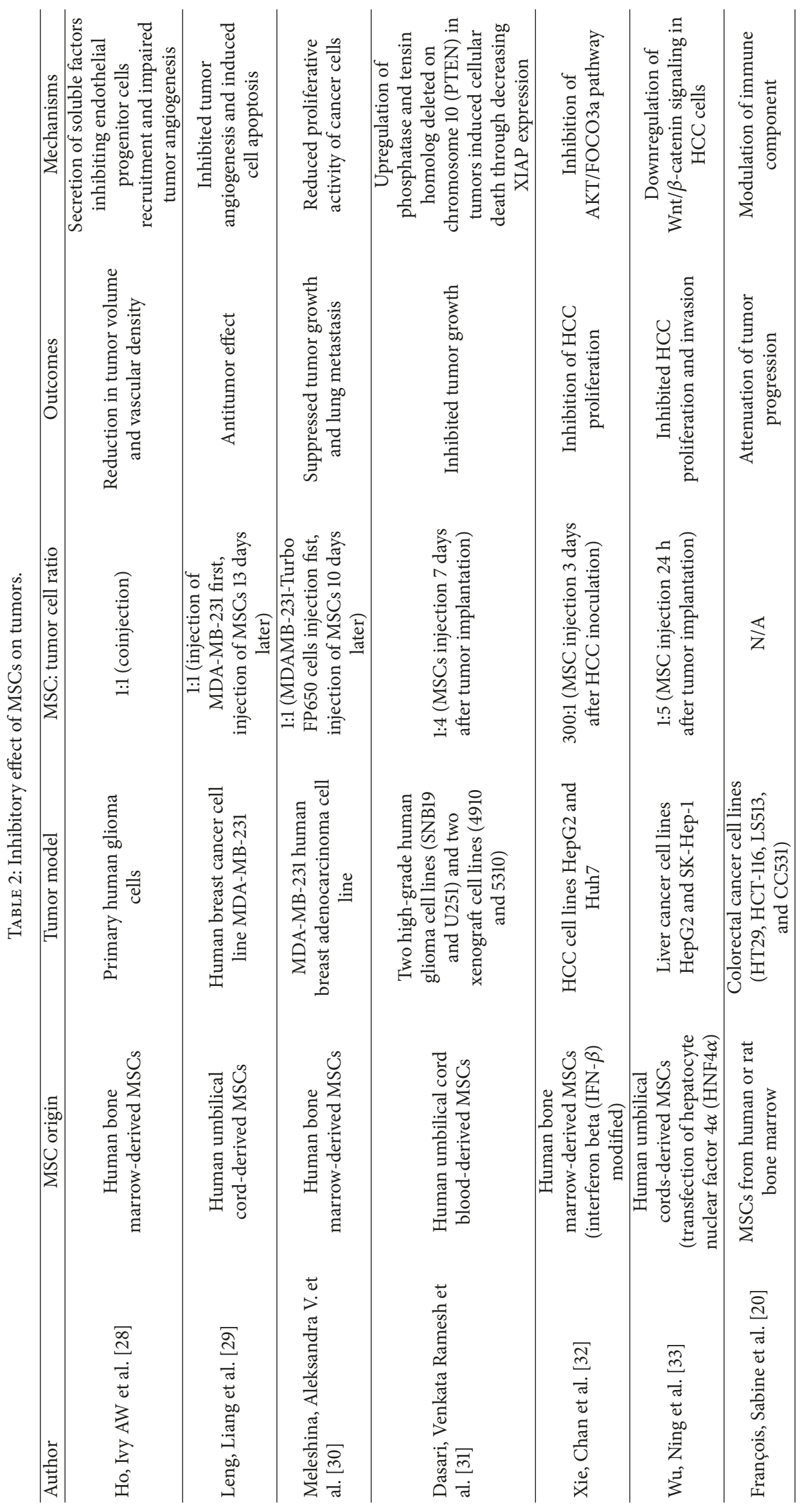


that tumor cells secret chemokines, cytokines, and growth factors recruiting MSCs into the tumor sites. In turn, MSCs, as a component of tumor microenvironment, affect tumor growth and metastasis through secretion of cytokines and chemokines [52, 53]. Thus, the process of tumor progression has been regarded as a result of an evolving crosstalk between different cell types within the tumor and its surrounding host tissue and organ or tumor stroma [54].

Cancer stem cells (CSCs), which possess chemotherapy resistance, have been considered as the root of cancers and can resist chemotherapy, explaining cancer recurrence even many years after therapy is ended. The evidence that CSCs selectively resist therapy is provided by a multitude of observations in cell culture, animal models, and cancer patients. For example, direct analysis of apoptosis during cell culture showed that differentiated colon cancer cells are induced to die after chemotherapy, while CSCs from the same culture survive after toxic damage. Moreover, these surviving CSCs are able to reestablish the culture, indicating that they are responsible for therapy failure [55]. Chemotherapyresistant CD133+ CSCs were also observed in lung and liver cancer $[56,57]$. Similarly, the phenomenon of CSCs escape from therapy was also observed in xenograft studies. Chemotherapy treatment of xenotransplanted CSCs leads to an increase in CD133+ CSCs in the tumor [58]. This showed that CD133+ CSCs are more resistant to chemotherapy drugs in vivo compared to differentiated CD133+ cells. And breast CSCs and GBM CSCs isolated from patient specimens have showed selective resistance to a variety of chemotherapies $[59,60]$.

Furthermore, various studies have shown that the tumor stroma plays important roles in the survival, growth, and metastatic progression of cancer. In the hypoxic environment, the tumor stroma can increase its secretion of signaling proteins such as tumor necrosis factor- $\alpha$ (TNF- $\alpha$ ), TGF$\beta$, PDGF, and hepatocyte growth factor (HGF) [61]. In the meanwhile, tumor oxygenation status is tightly associated with its aggressive behavior. Experimental solid tumors contain a significant fraction of microregions that are chronically or transiently hypoxic. Hypoxia plays critical roles in tumor progression including tumor angiogenesis, mutation rate, metastasis and resistance to radiation and chemotherapy [62]. Many molecular pathways have been demonstrated to mediate these hypoxia-induced responses in tumors. Among them, hypoxia-inducible factor-1 (HIF-1) is a key signaling pathway regulating tumor responses to hypoxia [63]. Transiently hypoxic microenvironment in solid tumor may represent the stem cell niche to some extent, in which HIF$1 \alpha$ stabilization and activation of stromal-cell derived factor1 (SDF1), VEGF, and Chemokine (C-X-C motif) Receptor 4 (CXCR4) occur, attracting MSCs homing and recruitment consequently $[64,65]$. Furthermore, the state of tumorinduced hypoxia, which often perpetuates the inflammatory state, induces the secretion of numerous growth factors (e.g., endothelial growth factor-A, and fibroblast growth factor), thereby inducing MSCs recruitment and tumor growth through stimulation of tumor angiogenesis $[23,66]$. The cancer microenvironment, MSCs, and CSCs are illustrated in Figure 1.

\section{MSCs and Antitumor Therapy}

3.1. MSCs-Derived Exosomes as Vehicles for Antitumor Ther$a p y$. Exosomes are nano-sized $(<100 \mathrm{~nm})$ and lipid-bilayerenclosed extracellular vesicles that are released by many types of cells. They are found to play critical roles in intercellular communication via the transfer of genetic molecules such as mRNA and microRNAs, as well as proteins [67]. A common characteristic of human cancers is the aberrant expressions of either oncogenes, oncomiRs, or tumor suppressors. The MSCs-derived exosomes which contain a variety of miRNAs can be taken up by cancer cells and function in them. For example, miR-100 has been found to be downregulated in all subtypes of breast cancer, including the luminal A, luminal $\mathrm{B}$, basal-like, and human epidermal growth factor receptor 2 (HER2) subtypes [34]. It is enriched in MSCs-derived exosomes and could suppress in vitro angiogenesis through modulating the mTOR/HIF- $1 \alpha /$ VEGF signaling axis in breast cancer cells [35].

However, to date, studies with controversial outcomes on MSC-derived exosomes in tumor progression have been reported, including promoted effects [36-38] and suppressive effects $[68,69]$, as summarized in Table 3 . The controversy effects of MSCs-derived exosomes may result from different tissue-derived MSCs used and different component of exosomes applied, different protocols applied for exosome collection, as well as different cancer model and stages of cancer studied. In addition, there is also another issue that the exosomes secreted by MSCs are not created equal. Thus, comprehensive studies are required to advance our knowledge and concerns over cancer research and treatment using MSCs-derived exosomes. One possible approach for clinical application of MSCs-derived exosomes for cancer treatment is that MSCs should be genetically engineered for stable expression of some cancer killer genes before the isolation of exosomes from MSCs, just as Sueon Kim et al. reported for generating antigen-specific $\mathrm{CD} 8+\mathrm{T}$ cells for adoptive cell therapies against viral infection and tumors [70].

3.2. MSCs as Vehicles for Antitumor Therapy. MSCs have the characteristics of tumor tendency and avoidance of immune clearance; thus, it is promising that MSCs are utilized as vehicles to deliver anticancer treatments [71]. It has been demonstrated in a number of preclinical in vitro migration experiments and in various tumor models, such as hepatoma [72], leukemia cells [73], breast cancer [52], and osteosarcoma [74]. It may be an appropriate strategy that MSCs carrying anticancer drugs targeted treatment of tumors. For example, Bonomi et al. observed that MSCs-Paclitaxel (PTX) inhibit the proliferation of human myeloma cells in vitro 3D dynamic culture system [75]. The anticancer effect of MSCs-PTX has also been shown on pancreatic carcinoma cells in vitro [76]. MSCs are also promising tool for cisplatin (CDDP) delivery towards the tumor [71]. In addition, researches have shown that MSCs with suicide genes or apoptotic genes targeting for tumor is a promising approach. In vivo and in vitro studies have shown that the expression of interferon- $\gamma$ in MSCs transfected by adenovirus can effectively kill glioma cells [77]. It is worth noting that in a model of lung metastasis 


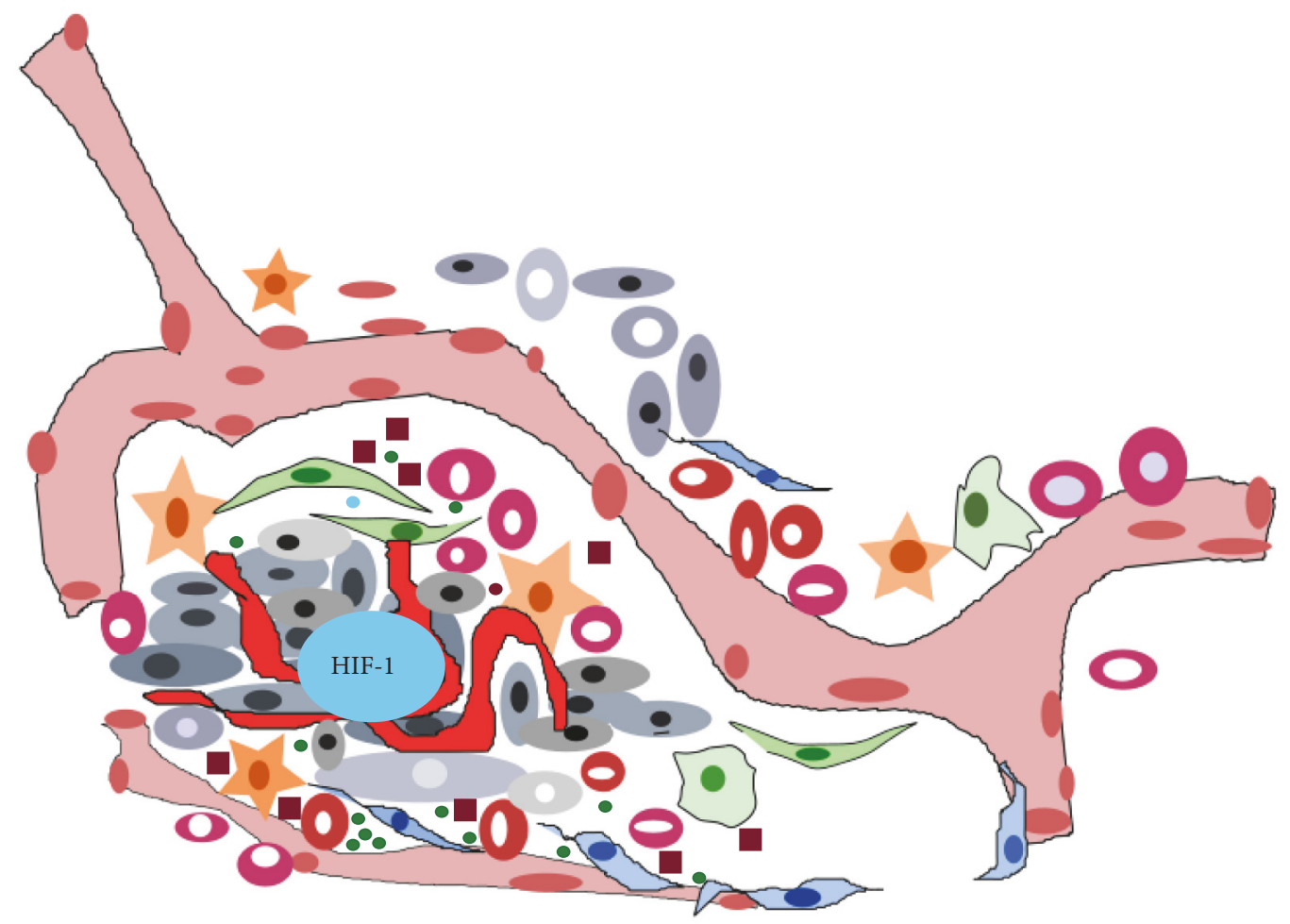

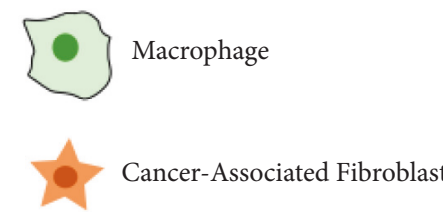

Cancer Stem Cells

New Blood Vessel
Lymphocytes

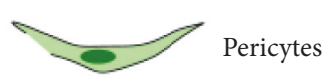

Neutrophil

SDF-1
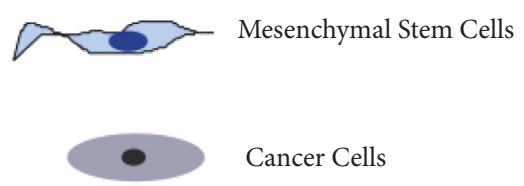

Endothelial Cell

VEGF

FIGURE 1: The primary tumor microenvironment. Cancer cells in primary tumors are surrounded by a complex microenvironment that consists of numerous cells, including endothelial cells of the blood vessel, cancer-associated fibroblast, lymphocytes, neutrophil, MSCs, macrophages, cancer stem cells, and pericytes. Solid tumors contain a significant fraction of microregions that are chronically or transiently hypoxic, in which HIF-1 associated signaling pathway is activated, thus inducing the expression of various downstream genes, including VEGF and SDF-1.

of prostate cancer, MSCs expressing IFN- $\beta$ could prolong the survival period, and its possible mechanism is that IFN$\beta$ could promote tumor cell apoptosis, inhibit angiogenesis, and increase the activity of natural killer cells [78]. Similarly, adenovirus-transfected MSCs expressing interferon- $\gamma$ inhibit proliferation of leukemia cells and induce apoptosis of leukemia cells in vitro [79]. In models of lung metastatic carcinoma, a study has found that MSCs carrying TNF-related apoptosis-inducing ligand (TRAIL) reduce tumor growth and recurrence and inhibit the growth of lung metastatic foci in most mice [80]. Study has reported that in glioma mice, tumor tropism of umbilical cord MSCs carrying TRAIL was enhanced after irradiation and its proapoptotic effect on tumor cells was enhanced by MSCs-TRAIL [81]. In addition, the previous and our studies also have demonstrated that MSCs could be genetically modified with herpes 
TABLE 3: Effects of MSCs-derived exosomes on tumors.

\begin{tabular}{|c|c|c|c|c|}
\hline Author & Exosome origin & Tumor model & Outcomes & Mechanisms \\
\hline Li, Hongdan et al. [34] & $\begin{array}{l}\text { Human bone marrow } \\
\text { MSCs from patients } \\
\text { undergoing } \\
\text { hip-replacement surgery }\end{array}$ & $\begin{array}{c}\text { Colon cancer cells } \\
\text { (HCT-116, HT-29, and } \\
\text { SW-480) }\end{array}$ & $\begin{array}{l}\text { Increased the } \\
\text { population of colon } \\
\text { cancer stem cells }\end{array}$ & $\begin{array}{l}\text { miR-142-3p in exosomes } \\
\text { promoted the Notch } \\
\text { signaling pathways by } \\
\text { downregulating Numb }\end{array}$ \\
\hline Zhang, Yanling et al. [35] & $\begin{array}{c}\text { Human omental } \\
\text { adipose-derived MSCs } \\
\text { from cancer-free female } \\
\text { donors }\end{array}$ & $\begin{array}{c}\text { Human EOC cell lines } \\
\text { (SKOV3, A2780, and } \\
\text { HO-8910) }\end{array}$ & $\begin{array}{l}\text { Promoted cancer } \\
\text { progression }\end{array}$ & $\begin{array}{c}\text { Affect proteomic profile } \\
\text { of tumor cells via } \\
\text { paracrine mechanism }\end{array}$ \\
\hline Roccaro AM et al. [36] & $\begin{array}{l}\text { Human bone marrow } \\
\text { MSCs from normal or } \\
\text { cancer patients }\end{array}$ & $\begin{array}{l}\text { Multiple myeloma (MM) } \\
\text { cells }\end{array}$ & $\begin{array}{c}\text { MM } \\
\text { BM-MSCs-derived } \\
\text { exosomes promoted } \\
\text { MM tumor growth, } \\
\text { normal BM-MSC } \\
\text { exosomes inhibited } \\
\text { the growth of MM } \\
\text { cells }\end{array}$ & $\begin{array}{l}\text { Impact MM cell } \\
\text { adhesion }\end{array}$ \\
\hline Makiko Ono et al. [37] & $\begin{array}{c}\text { Human bone marrow } \\
\text { MSCs }\end{array}$ & BM2 cells & Slowed tumor growth & $\begin{array}{c}\text { Exosomal } \\
\text { transfer of miR-23b and } \\
\text { its suppression of } \\
\text { MARCKS }\end{array}$ \\
\hline Reza AM et al. [38] & Human adipose MSCs & $\begin{array}{c}\text { A2780 and SKOV-3 ovarian } \\
\text { cancer cells }\end{array}$ & $\begin{array}{c}\text { Inhibited } \\
\text { proliferation of } \\
\text { ovarian cancer cells }\end{array}$ & $\begin{array}{c}\text { Upregulates } \\
\text { proapoptotic molecules }\end{array}$ \\
\hline
\end{tabular}

simplex virus thymidine kinase (HSV-TK), and the cancer cells could be killed by HSV-TK/GCV suicide gene therapy [82-84]. A recent study showed that histone deacetylase inhibitors (HDACis) induced apoptosis of chemoresistant cells effectively, like CD123/CD47-positive cells, which were found as maybe serving as a key role for chemoresistance in tumor microenvironment. Furthermore, HDACis efficiently targeted and removed chemoresistant leukemia blasts in a xenograft AML mouse model [85].

The immune system plays an important role in monitoring the growth of malignant cells. Therefore, stimulating the body's own immune system for antitumor treatment is a highly promising strategy. Interleukins (ILs) are cytokines that regulate inflammation and immune response and have been shown to exhibit antitumor effects through direct tumor-killing or active regulation of the endogenous immune system [86]. MSCs have been utilized to deliver interleukins that can improve the anticancer immune surveillance by activating NK cells and cytotoxic lymphocytes [86]. For example, the IL-18 secreted MSCs were correlative with enhanced T cell infiltration and antitumor immunity in mice bearing invasive and noninvasive gliomas [87]. Similarly, MSCs engineered to express IL-12 prevented metastasis into the lymph nodes and other internal organs as well as increased tumor cell apoptosis in mice bearing preestablished metastases of melanoma, breast, and hepatoma tumors [88]. Also, MSCs engineered to express IL-12 was tested in different mouse tumor models of melanoma and glioma [46]. Other immune-stimulatory molecules, like CX3C chemokine fractalkine (CX3CL), have also been engineered in MSCs. CX3CL1 is known as a strong $\mathrm{T}$ cell chemoattractant. Recent studies reveal that CX3CL1 is a driver of $\mathrm{T}$ cell migration to the omentum in esophagogastric adenocarcinoma (EAC). Previous research has shown that injection of an adenoviral vector expressing CX3CL1 can induce strong antitumor immune responses by activating both NK cells and T cells [89]. Similarly, intravenous or intratracheal delivery of MSCs-CX3CL1, activating T cells and $\mathrm{NK}$ cells, was observed to strongly inhibit process of lung metastasis and increase survival of mice carrying lung metastases cells $[90,91]$. Taken together, the tumortrophic homing capacity makes MSCs ideal cellular delivery vehicles for personalized cell-based targeted-cancer gene therapy. And the strategies of targeted-cancer therapy were summarized in Figure 2.

3.3. Inhibition of Migration for Antitumor Therapy. Tumor has been seen as a "wound that never heals" which enrolls MSCs in its microenvironment through production of paracrine and endocrine signals. So theoretically, inhibition of MSCs homing will prevent the growth of tumor. For instance, PDGF receptor $\beta$ (PDGFR $\beta$ ) has been reported to play an important role in recruitment of MSCs towards tumor sites [92]. And Simona Camorani et al. have demonstrated that interfere with the PDGFR $\beta$-mediated crosstalk between BM-MSCs and tumor cells using a nuclease-resistant RNA aptamer could inhibit the migration of MSCs towards tumor cells and hampering tumor aggressiveness [93]. The classic signaling governing MSCs homing is SDF1-CXCR4 axis. SDF1 is highly expressed in active multiple myeloma, as well as in bone marrow sites of tumor metastasis, neutralizing SDF1 with a highaffinity L-RNA Spiegelmer to SDF-1 has been demonstrated to diminish the disease progression [94]. In tumor biology, a number of studies observed the requirement of Akt and Wnt signaling for the migration, invasion, and survival of 


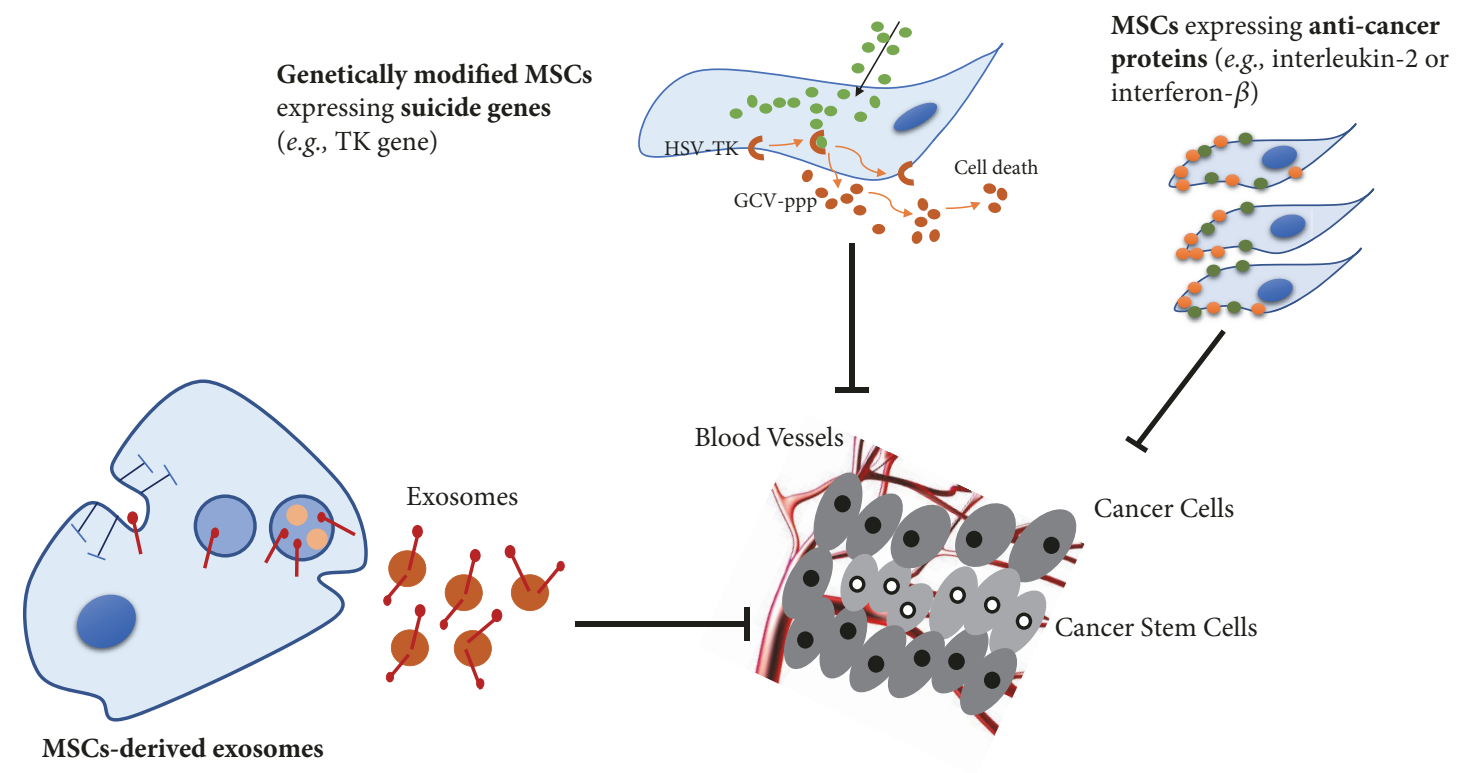

FIGURE 2: Strategies of targeted-cancer therapy. MSCs have been utilized as vehicles to deliver anticancer treatments due to their tumor-tropic property. Genetically modified MSCs expressing suicide genes (e.g., TK gene) have been used to treat cancer effectively in vitro and in vivo through inducing cell death. Additionally, MSCs can be induced to express anticancer proteins (e.g., IL- 2 or IFN- $\beta$ ), to generate prodrug activating enzymes or to deliver oncolytic viruses and the active drug for tumor-targeting. Simultaneously, MSCs-derived exosomes also suppressed tumor growth.

tumor cells [95-97]. Recent studies have shown that MSCs are involved in mediating these signaling pathways to influence migration of tumors. In glioma cells and in the nude mice tumors, upregulation of PTEN by hUCBSC downregulated Akt and (phosphoinositide 3-kinase) PI3K signaling pathway results in the inhibition of migration [98]. Similarly, results of a study demonstrated that overexpression of $\mathrm{HNF} 4 \alpha$ suppresses HCC progression by reducing hepatoma cell growth and metastasis through downregulating the $\mathrm{Wnt} / \beta$-catenin signaling pathway [99].

\section{Clinical Trials of MSCs in Cancer Therapy}

A small number of registered clinical trials for the treatment of solid tumors with MSCs are underway. These trials have been inspired by successful preclinical trials, although some results have not been published yet. The first clinical trial of gastrointestinal tumors worldwide utilizing genetically engineered MSCs in humans has been reported (TREATME1) [100]; this trial uses MSCs-delivery of HSV-TK under the control of the CCL5 promoter. This is a successful phase I/II clinical trial. Another two registered clinical trials with MSCs have primarily focused on ovarian cancer. One of them is a phase I clinical trial sponsored by M.D. Anderson Cancer Center, in which human MSCs transfected with interferon beta (MSCs-IFN $\beta$ ). The purposes of this clinical trial are to test the safety of MSCs-IFN $\beta$ and to find the highest tolerable dose of human MSCs-IFN $\beta$ that can be given to patients with ovarian cancer. Similarly, Mayo Clinic initiated a phase I/II trial to find the side effects and best dose of MSCs infected with oncolytic measles virus encoding NIS (MV-NIS) and to observe its effect on patients with ovarian cancer. In a clinical approach for the treatment of lung cancer, allogeneic MSCs expressing a full length version of TRAIL have been used. MSCs as gene-therapeutic vehicle aim to deliver the TRAIL. In addition, one clinical trial for treating liver cancer with MSCs is on the registry and is recruiting subjects. The purpose of this trial was to study whether MSCs may influence the outcome of graft versus host response in liver transplantation of liver cancer patients. In a phase I clinical test, allogeneic bone marrow-derived MSCs were infused in men with localized prostate cancer [101]. The primary objective was to assess safety and cancer-homing ability of MSCs. However, in this study, MSCs did not home primary tumors in sufficient levels to kill cancer cells or inhibit tumor growth. Although the treatment results have not been published or have not achieved the expected objectives, more attention and patience are needed to promote the clinical transformation of MSCs in tumor treatment. In summary, MSCs and their secreted exosomes have great potential for tumor therapy. Meanwhile, to accelerate the transformation from preclinical research to clinical application, more efficacy and safety of these therapeutic approaches need to be provided by preclinical studies.

\section{Conclusions and Prospective}

This article primarily discusses the recent progress of the complex roles of multipotent MSCs in tumor microenvironment, progression, and potential clinical applications. The function of CSCs in tumor microenvironment should be paid more attention to, which is critical for development of cancer cells. The roles of miRNAs and signaling pathways in tumor microenvironment need to be intensively studied, which may 
provide us with new means to accurately treat cancer. We should also pay more attention to the molecular mechanism of antitumorogenic activity of MSCs, which may improve the precision of targeted therapy. Importantly, reducing the growth stimulation and malignant transformation of MSCs in tumor targeted therapy will accelerate clinical transformation.

\section{Abbreviations}

$\begin{array}{ll}\text { ADSCs: } & \text { Adipose-derived stem cells } \\ \text { ASCs: } & \text { Adipose stromal cells } \\ \text { BC: } & \text { Breast cancer } \\ \text { CSCs: } & \text { Cancer stem cells } \\ \text { CXCR4: } & \text { Chemokine (C-X-C motif) Receptor type } \\ & 4 \\ \text { CTL: } & \text { Cytotoxic T lymphocyte } \\ \text { CX3CL: } & \text { CX3C chemokine fractalkine } \\ \text { EAC: } & \text { Esophagogastric adenocarcinoma } \\ \text { hBM-MSCs: } & \text { Human fetal bone marrow stem cells } \\ \text { HCC: } & \text { Hepatocellular carcinoma } \\ \text { HER2: } & \text { Growth factor receptor 2 } \\ \text { HGF: } & \text { Hepatocyte growth factor } \\ \text { HIFs: } & \text { Hypoxia-inducible factors } \\ \text { hUCMSCs: } & \text { Human umbilical cord MSCs } \\ \text { HSV-TK: } & \text { Herpes simplex virus thymidine kinase } \\ \text { hUCMSC-EVs: } & \text { hUCMSC-derived extracellular vesicles } \\ \text { IL-6: } & \text { Interleukin-6 } \\ \text { IFN- } \beta: & \text { Interferon beta } \\ \text { LUAD: } & \text { Lung adenocarcinoma } \\ \text { LOX: } & \text { Lysyl oxidase } \\ \text { MSCs: } & \text { Mesenchymal stem cells } \\ \text { NK cells: } & \text { Natural killer cells } \\ \text { PDGF: } & \text { Platelet-derived growth factor } \\ \text { PI3K: } & \text { Phosphoinositide 3-kinase } \\ \text { PDGFR } \beta: & \text { PDGF receptor } \beta \\ \text { PTEN: } & \text { Phosphatase and tensin homolog deleted } \\ & \text { on chromosome 10 } \\ \text { PTX: } & \text { Paclitaxel } \\ \text { SDF1: } & \text { Stromal-cell derived factor-1 } \\ \text { TGF- } \beta: & \text { Transforming growth factor- } \beta \\ \text { TNF- } \alpha: & \text { Tumor necrosis factor- } \alpha \\ \text { TRAIL: } & \text { TNF-related apoptosis-inducing ligand } \\ \text { VEGF: } & \text { Vascular endothelial growth factor. } \\ & \\ & \end{array}$

\section{Conflicts of Interest}

The authors declare no financial conflicts of interest.

\section{Authors' Contributions}

Weiping Lin and Linfeng Huang contributed equally as the first authors.

\section{Acknowledgments}

We apologize for the works not cited in the text owing to space restriction. This work was supported by National Natural
Science Foundation of China (grant number 81473696, 81673999) and National Natural Science Foundation of Guangdong Province (grant number 2015A030313361; 2017A050506046). This work was also partially supported by the Guangdong Natural Science Funds for Distinguished Young Scholars (2015A030306037).

\section{References}

[1] A. J. Friedenstein, "Precursor cells of mechanocytes," International Review of Cytology-A Survey Of Cell Biology, vol. 47, pp. 327-359, 1976.

[2] A. J. Friedenstein, R. K. Chailakhjan, and K. S. Lalykina, “The development of fibroblast colonies in monolayer cultures of guinea-pig bone marrow and spleen cells," Cell Tissue Kinet, vol. 3, no. 4, pp. 393-403, 1970.

[3] M. B. Murphy, K. Moncivais, and A. I. Caplan, "Mesenchymal stem cells: environmentally responsive therapeutics for regenerative medicine," Experimental \& Molecular Medicine, vol. 45, no. 11, article e54, 2013.

[4] P. A. Zuk, M. Zhu, H. Mizuno et al., "Multilineage cells from human adipose tissue: implications for cell-based therapies," Tissue Engineering Part A, vol. 7, no. 2, pp. 211-228, 2001.

[5] J. J. Minguell, A. Erices, and P. Conget, "Mesenchymal stem cells," Experimental Biology and Medicine, vol. 226, no. 6, pp. 507-520, 2001.

[6] C. Nombela-Arrieta, J. Ritz, and L. E. Silberstein, "The elusive nature and function of mesenchymal stem cells," Nature Reviews Molecular Cell Biology, vol. 12, no. 2, pp. 126-131, 2011.

[7] M. Dominici, K. Le Blanc, I. Mueller et al., "Minimal criteria for defining multipotent mesenchymal stromal cells. the international society for cellular therapy position statement," Cytotherapy, vol. 8, no. 4, pp. 315-317, 2006.

[8] Y. Wang, X. Chen, W. Cao, and Y. Shi, "Plasticity of mesenchymal stem cells in immunomodulation: pathological and therapeutic implications," Nature Immunology, vol. 15, no. 11, pp. 1009-1016, 2014.

[9] J. A. Ankrum, J. F. Ong, and J. M. Karp, "Mesenchymal stem cells: immune evasive, not immune privileged," Nature Biotechnology, vol. 32, no. 3, pp. 252-260, 2014.

[10] J. P. A. Gomes, A. F. Assoni, M. Pelatti, G. Coatti, S. K. Okamoto, and M. Zatz, "Deepening a simple question: Can MSCs be used to treat cancer?" Anticancer Reseach, vol. 37, no. 9, pp. 47474758, 2017.

[11] R. S. Y. Wong, "Mesenchymal stem cells: angels or demons?" Journal of Biomedicine and Biotechnology, vol. 2011, Article ID 459510, 8 pages, 2011.

[12] T. Liu, K. Zhu, C. Ke et al., "Mesenchymal stem cells inhibited development of lung cancer induced by chemical carcinogens in a rat model," American Journal of Translational Research, vol. 9, no. 6, pp. 2891-2900, 2017.

[13] Y. Yulyana, I. A. W. Ho, K. C. Sia et al., "Paracrine factors of human fetal MSCs inhibit liver cancer growth through reduced activation of IGF-1R/PI3K/Akt signaling," Molecular Therapy, vol. 23, no. 4, pp. 746-756, 2015.

[14] S. Kidd, L. Caldwell, M. Dietrich et al., "Mesenchymal stromal cells alone or expressing interferon-beta suppress pancreatic tumors in vivo, an effect countered by anti-inflammatory treatment," Cytotherapy, vol. 12, no. 5, pp. 615-625, 2010. 
[15] S. M. Albarenque, R. M. Zwacka, and A. Mohr, "Both human and mouse mesenchymal stem cells promote breast cancer metastasis," Stem Cell Research, vol. 7, no. 2, pp. 163-171, 2011.

[16] K. Shinagawa, Y. Kitadai, M. Tanaka et al., "Mesenchymal stem cells enhance growth and metastasis of colon cancer," International Journal of Cancer, vol. 127, no. 10, pp. 2323-2333, 2010.

[17] P. Chaturvedi, D. M. Gilkes, C. C. Wong et al., "Hypoxiainducible factor-dependent breast cancer-mesenchymal stem cell bidirectional signaling promotes metastasis," The Journal of Clinical Investigation, vol. 123, no. 1, pp. 189-205, 2013.

[18] W. Zhong, Y. Tong, Y. Li et al., "Mesenchymal stem cells in inflammatory microenvironment potently promote metastatic growth of cholangiocarcinoma via activating Akt/NF-kappaB signaling by paracrine CCL5," Oncotarget, vol. 8, no. 43, pp. 73693-73704, 2017.

[19] R. Lee, N. Yoon, J. Reneau, and D. Prockop, "Preactivation of human MSCs with TNF-alpha enhances tumor-suppressive activity," Cell Stem Cell, vol. 11, no. 6, pp. 825-835, 2012.

[20] S. François, B. Usunier, M. Forgue-Lafitte et al., "Mesenchymal stem cell administration attenuates colon cancer progression by modulating the immune component within the colorectal tumor microenvironment," Stem Cells Translational Medicine, vol. 8, no. 3, pp. 285-300, 2019.

[21] M. Walter, S. Liang, S. Ghosh, P. J. Hornsby, and R. Li, "Interleukin 6 secreted from adipose stromal cells promotes migration and invasion of breast cancer cells," Oncogene, vol. 28, no. 30, pp. 2745-2755, 2009.

[22] K. S. Tsai, S. H. Yang, Y. P. Lei et al., "Mesenchymal stem cells promote formation of colorectal tumors in mice," Gastroenterology, vol. 141, no. 3, pp. 1046-1056, 2011.

[23] T. Zhang, Y. W. Lee, Y. F. Rui, T. Y. Cheng, X. H. Jiang, and G. Li, "Bone marrow-derived mesenchymal stem cells promote growth and angiogenesis of breast and prostate tumors," Stem Cell Research \& Therapy, vol. 4, no. 3, article 70, 2013.

[24] C. P. El-Haibi, G. W. Bell, J. Zhang et al., "Critical role for lysyl oxidase in mesenchymal stem cell-driven breast cancer malignancy," Proceedings of the National Acadamy of Sciences of the United States of America, vol. 109, no. 43, pp. 17460-17465, 2012.

[25] S. A. Patel, J. R. Meyer, S. J. Greco, K. E. Corcoran, M. Bryan, and P. Rameshwar, "Mesenchymal Stem Cells Protect Breast Cancer Cells through Regulatory T Cells: Role of Mesenchymal Stem Cell-Derived TGF-beta," The Journal of Immunology, vol. 184, no. 10, pp. 5885-5894, 2010.

[26] E. M. Chandler, B. R. Seo, J. P. Califano et al., "Implanted adipose progenitor cells as physicochemical regulators of breast cancer," Proceedings of the National Acadamy of Sciences of the United States of America, vol. 109, no. 25, pp. 9786-9791, 2012.

[27] M. E. Gonzalez, E. E. Martin, T. Anwar et al., "Mesenchymal stem cell-induced DDR2 mediates stromal-breast cancer interactions and metastasis growth," Cell Reports, vol. 18, no. 5, pp. 1215-1228, 2017.

[28] I. A. W. Ho, H. C. Toh, W. H. Ng et al., "Human bone marrow-derived mesenchymal stem cells suppress human glioma growth through inhibition of angiogenesis," Stem Cells, vol. 31, no. 1, pp. 146-155, 2013.

[29] L. Leng, Y. Wang, N. He et al., "Molecular imaging for assessment of mesenchymal stem cells mediated breast cancer therapy," Biomaterials, vol. 35, no. 19, pp. 5162-5170, 2014.
[30] A. V. Meleshina, E. I. Cherkasova, M. V. Shirmanova et al., "Influence of mesenchymal stem cells on metastasis development in mice in vivo," Stem Cell Research \& Therapy, vol. 6, no. $1,2015$.

[31] V. R. Dasari, K. Kaur, K. K. Velpula et al., "Upregulation of PTEN in Glioma Cells by Cord Blood Mesenchymal Stem Cells Inhibits Migration via Downregulation of the PI3K/Akt Pathway," PLoS ONE, vol. 5, no. 4, Article ID e10350, 2010.

[32] C. Xie, D.-Y. Xie, B.-L. Lin et al., "Interferon-beta gene-modified human bone marrow mesenchymal stem cells attenuate hepatocellular carcinoma through inhibiting AKT/FOXO3a pathway," British Journal of Cancer, vol. 109, no. 5, pp. 1198-1205, 2013.

[33] N. Wu, Y. L. Zhang, H. T. Wang et al., "Overexpression of hepatocyte nuclear factor 4 alpha in human mesenchymal stem cells suppresses hepatocellular carcinoma development through Wnt/beta-catenin signaling pathway downregulation," Cancer Biology \& Therapy, vol. 17, no. 5, pp. 558-565, 2016.

[34] D. Chen, Y. Sun, Y. Yuan et al., "miR-100 induces epithelialmesenchymal transition but suppresses tumorigenesis, migration and invasion," PLoS Genetics, vol. 10, no. 2, Article ID e1004177, 2014.

[35] K. Pakravan, S. Babashah, M. Sadeghizadeh et al., "MicroRNA100 shuttled by mesenchymal stem cell-derived exosomes suppresses in vitro angiogenesis through modulating the mTOR/HIF-1alpha/VEGF signaling axis in breast cancer cells," Cellular Oncology, vol. 40, no. 5, pp. 457-470, 2017.

[36] H. Li and F. Li, "Exosomes from BM-MSCs increase the population of CSCs via transfer of miR-142-3p," British Journal of Cancer, vol. 119, no. 6, pp. 744-755, 2018.

[37] A. M. Roccaro, A. Sacco, P. Maiso et al., "BM mesenchymal stromal cell-derived exosomes facilitate multiple myeloma progression," The Journal of Clinical Investigation, vol. 123, no. 4, pp. 1542-1555, 2013.

[38] Y. Zhang, W. Dong, J. Wang, J. Cai, and Z. Wang, "Human omental adipose-derived mesenchymal stem cell-conditioned medium alters the proteomic profile of epithelial ovarian cancer cell lines in vitro," OncoTargets and Therapy, vol. 10, pp. 16551663, 2017.

[39] W. Wang, W. Zhong, J. Yuan et al., "Involvement of Wnt/betacatenin signaling in the mesenchymal stem cells promote metastatic growth and chemoresistance of cholangiocarcinoma," Oncotarget, vol. 6, no. 39, pp. 42276-42289, 2015.

[40] H. D. Lin, C.-Y. Fong, A. Biswas, M. Choolani, and A. Bongso, "Human umbilical cord wharton's jelly stem cell conditioned medium induces tumoricidal effects on lymphoma cells through hydrogen peroxide mediation," Journal of Cellular Biochemistry, vol. 117, no. 9, pp. 2045-2055, 2016.

[41] R. Ramasamy, E. W. Lam, I. Soeiro, V. Tisato, D. Bonnet, and F. Dazzi, "Mesenchymal stem cells inhibit proliferation and apoptosis of tumor cells: impact on in vivo tumor growth," Leukemia, vol. 21, no. 2, pp. 304-310, 2007.

[42] E. L. Spaeth, J. L. Dembinski, A. K. Sasser et al., "Mesenchymal stem cell transition to tumor-associated fibroblasts contributes to fibrovascular network expansion and tumor progression," PLoS ONE, vol. 4, no. 4, Article ID e4992, 2009.

[43] D. Bexell, S. Gunnarsson, A. Tormin et al., "Bone marrow multipotent mesenchymal stroma cells act as pericyte-like migratory vehicles in experimental gliomas," Molecular Therapy: The Journal of the American Society of Gene Therapy, vol. 17, no. 1, pp. 183-190, 2009.

[44] L. Dong, Y. Pu, L. Zhang et al., "Human umbilical cord mesenchymal stem cell-derived extracellular vesicles promote 
lung adenocarcinoma growth by transferring miR-410," Cell Death \& Disease, vol. 9, no. 2, p. 218, 2018.

[45] M. Wang, C. Zhao, H. Shi et al., "Deregulated microRNAs in gastric cancer tissue-derived mesenchymal stem cells: novel biomarkers and a mechanism for gastric cancer," British Journal of Cancer, vol. 110, no. 5, pp. 1199-1210, 2014.

[46] K. Nakamura, Y. Ito, Y. Kawano et al., "Antitumor effect of genetically engineered mesenchymal stem cells in a rat glioma model," Gene Therapy, vol. 11, no. 14, pp. 1155-1164, 2004.

[47] C. Qiao, W. Xu, W. Zhu et al., "Human mesenchymal stem cells isolated from the umbilical cord," Cell Biology International, vol. 32, no. 1, pp. 8-15, 2008.

[48] L. Qiao, Z. Xu, T. Zhao et al., "Suppression of tumorigenesis by human mesenchymal stem cells in a hepatoma model," Cell Research, vol. 18, no. 4, pp. 500-507, 2008.

[49] K. Otsu, S. Das, S. D. Houser, S. K. Quadri, S. Bhattacharya, and J. Bhattacharya, "Concentration-dependent inhibition of angiogenesis by mesenchymal stem cells," Blood, vol. 113, no. 18, pp. 4197-4205, 2009.

[50] A. Y. Khakoo, S. Pati, S. A. Anderson et al., "Human mesenchymal stem cells exert potent antitumorigenic effects in a model of Kaposi's sarcoma," The Journal of Experimental Medicine, vol. 203, no. 5, pp. 1235-1247, 2006.

[51] A. F. Chambers, A. C. Groom, and I. C. MacDonald, "Dissemination and growth of cancer cells in metastatic sites," Nature Reviews Cancer, vol. 2, no. 8, pp. 563-572, 2002.

[52] A. E. Karnoub, A. B. Dash, A. P. Vo et al., "Mesenchymal stem cells within tumour stroma promote breast cancer metastasis," Nature, vol. 449, no. 7162, pp. 557-563, 2007.

[53] W. Zhu, W. Xu, R. Jiang et al., "Mesenchymal stem cells derived from bone marrow favor tumor cell growth in vivo," Experimental and Molecular Pathology, vol. 80, no. 3, pp. 267$274,2006$.

[54] G. Lorusso and C. Rüegg, "The tumor microenvironment and its contribution to tumor evolution toward metastasis," Histochemistry and Cell Biology, vol. 130, no. 6, pp. 1091-1103, 2008.

[55] S. Colak, C. D. Zimberlin, and E. Fessler, "Decreased mitochondrial priming determines chemoresistance of colon cancer stem cells," Cell Death \& Differentiation, vol. 21, no. 7, pp. 1170-1177, 2014.

[56] G. Bertolini, L. Roz, P. Perego et al., "Highly tumorigenic lung cancer $\mathrm{CD}_{133^{+}}$cells display stem-like features and are spared by cisplatin treatment," Proceedings of the National Acadamy of Sciences of the United States of America, vol. 106, no. 38, pp. 16281-16286, 2009.

[57] S. Ma, T. K. Lee, B.-J. Zheng, K. W. Chan, and X.-Y. Guan, "CD133+ HCC cancer stem cells confer chemoresistance by preferential expression of the Akt/PKB survival pathway," Oncogene, vol. 27, no. 12, pp. 1749-1758, 2008.

[58] M. Todaro, M. P. Alea, A. B. di Stefano et al., "Colon cancer stem cells dictate tumor growth and resist cell death by production of interleukin-4," Cell Stem Cell, vol. 1, no. 4, pp. 389-402, 2007.

[59] A. Eramo, L. Ricci-Vitiani, A. Zeuner et al., "Chemotherapy resistance of glioblastoma stem cells," Cell Death \& Differentiation, vol. 13, no. 7, pp. 1238-1241, 2006.

[60] C. Ginestier, S. Liu, M. E. Diebel et al., "CXCR1 blockade selectively targets human breast cancer stem cells in vitro and in xenografts," The Journal of Clinical Investigation, vol. 120, no. 2, pp. 485-497, 2010.
[61] C. Scheel, T. Onder, A. Karnoub, R. A. Weinberg, and J. E. Talmadge, "Adaptation versus selection: the origins of metastatic behavior," Cancer Research, vol. 67, no. 24, pp. 11476-11480, 2007.

[62] I. Almendros and D. Gozal, "Intermittent hypoxia and cancer: undesirable bed partners?" Respiratory Physiology \& Neurobiology, vol. 256, pp. 79-86, 2018.

[63] P. Vaupel and A. Mayer, "Hypoxia in cancer: significance and impact on clinical outcome," Cancer and Metastasis Reviews, vol. 26, no. 2, pp. 225-239, 2007.

[64] C. Song and G. Li, "CXCR4 and matrix metalloproteinase-2 are involved in mesenchymal stromal cell homing and engraftment to tumors," Cytotherapy, vol. 13, no. 5, pp. 549-561, 2011.

[65] W. Lin, L. Xu, S. Zwingenberger, E. Gibon, S. B. Goodman, and G. Li, "Mesenchymal stem cells homing to improve bone healing," Journal of Orthopaedic Translation, vol. 9, pp. 19-27, 2017.

[66] E. Spaeth, A. Klopp, J. Dembinski, M. Andreeff, and F. Marini, "Inflammation and tumor microenvironments: defining the migratory itinerary of mesenchymal stem cells," Gene Therapy, vol. 15, no. 10, pp. 730-738, 2008.

[67] Y. Lee, S. El Andaloussi, and M. J. A. Wood, "Exosomes and microvesicles: extracellular vesicles for genetic information transfer and gene therapy," Human Molecular Genetics, vol. 21, no. 1, Article ID dds317, pp. R125-R134, 2012.

[68] A. M. M. T. Reza, Y.-J. Choi, H. Yasuda, and J.-H. Kim, "Human adipose mesenchymal stem cell-derived exosomal-miRNAs are critical factors for inducing anti-proliferation signalling to A2780 and SKOV-3 ovarian cancer cells," Scientific Reports, vol. 6, 2016.

[69] M. Ono, N. Kosaka, N. Tominaga et al., "Exosomes from bone marrow mesenchymal stem cells contain a microRNA that promotes dormancy in metastatic breast cancer cells," Science Signaling, vol. 7, no. 332, 2014.

[70] S. Kim, H.-J. Sohn, H.-J. Lee et al., "Use of engineered exosomes expressing HLA and costimulatory molecules to generate antigen-specific $\mathrm{CD} 8(+) \mathrm{T}$ cells for adoptive cell therapy," Journal of Immunotherapy, vol. 40, no. 3, pp. 83-93, 2017.

[71] D. S. Chulpanova, K. V. Kitaeva, L. G. Tazetdinova, V. James, A. A. Rizvanov, and V. V. Solovyeva, "Application of mesenchymal stem cells for therapeutic agent delivery in anti-tumor treatment," Frontiers in Pharmacology, vol. 9, p. 259, 2018.

[72] J. Zhang, L. Hou, X. Wu et al., "Inhibitory effect of genetically engineered mesenchymal stem cells with Apoptin on hepatoma cells in vitro and in vivo," Molecular and Cellular Biochemistry, vol. 416, no. 1-2, pp. 193-203, 2016.

[73] A. Pessina, V. Coccè, L. Pascucci et al., "Mesenchymal stromal cells primed with Paclitaxel attract and kill leukaemia cells, inhibit angiogenesis and improve survival of leukaemia-bearing mice," British Journal of Haematology, vol. 160, no. 6, pp. 766778, 2013.

[74] S. Duchi, G. Sotgiu, E. Lucarelli et al., "Mesenchymal stem cells as delivery vehicle of porphyrin loaded nanoparticles: effective photoinduced in vitro killing of osteosarcoma," Journal of Controlled Release, vol. 168, no. 2, pp. 225-237, 2013.

[75] A. Bonomi, N. Steimberg, A. Benetti et al., "Paclitaxel-releasing mesenchymal stromal cells inhibit the growth of multiple myeloma cells in a dynamic 3D culture system," Hematological Oncology, vol. 35, no. 4, pp. 693-702, 2017.

[76] A. T. Brini, V. Coccè, L. M. J. Ferreira et al., "Cell-mediated drug delivery by gingival interdental papilla mesenchymal stromal cells (GinPa-MSCs) loaded with paclitaxel," Expert Opinion on Drug Delivery, vol. 13, no. 6, pp. 789-798, 2016. 
[77] A. Nakamizo, F. Marini, T. Amano et al., "Human bone marrowderived mesenchymal stem cells in the treatment of gliomas," Cancer Research, vol. 65, no. 8, pp. 3307-3318, 2005.

[78] C. Ren, S. Kumar, D. Chanda et al., "Cancer gene therapy using mesenchymal stem cells expressing interferon-beta in a mouse prostate cancer lung metastasis model," Gene Therapy, vol. 15, no. 21, pp. 1446-1453, 2008.

[79] X. Li, Y. Lu, W. Huang et al., "In vitro effect of adenovirusmediated human Gamma Interferon gene transfer into human mesenchymal stem cells for chronic myelogenous leukemia," Hematological Oncology, vol. 24, no. 3, pp. 151-158, 2006.

[80] M. R. Loebinger, A. Eddaoudi, D. Davies, and S. M. Janes, "Mesenchymal stem cell delivery of TRAIL can eliminate metastatic cancer," Cancer Research, vol. 69, no. 10, pp. 41344142, 2009.

[81] S. M. Kim, J. H. Oh, S. A. Park et al., "Irradiation enhances the tumor tropism and therapeutic potential of tumor necrosis factor-related apoptosis-inducing ligand-secreting human umbilical cord blood-derived mesenchymal stem cells in glioma therapy," Stem Cells, vol. 28, no. 12, pp. 2217-2228, 2010.

[82] R. Uchibori, T. Okada, T. Ito et al., "Retroviral vector-producing mesenchymal stem cells for targeted suicide cancer gene therapy," The Journal of Gene Medicine, vol. 11, no. 5, pp. 373-381, 2009.

[83] W. Y. Lee, T. Zhang, C. P. Lau, C. C. Wang, K. M. Chan, and G. Li, "Immortalized human fetal bone marrow-derived mesenchymal stromal cell expressing suicide gene for antitumor therapy in vitro and in vivo," Cytotherapy, vol. 15, no. 12, pp. 1484-1497, 2013.

[84] C. Song, J. Xiang, J. Tang et al., “Thymidine kinase gene modified bone marrow mesenchymal stem cells as vehicles for antitumor therapy," Human Gene Therapy, vol. 22, no. 4, pp. 439-449, 2011.

[85] B. Yan, Q. Chen, K. Shimada et al., "Histone deacetylase inhibitor targets CD123/CD47-positive cells and reverse chemoresistance phenotype in acute myeloid leukemia," Leukemia, 2018.

[86] H. Okada and I. F. Pollack, "Cytokine gene therapy for malignant glioma," Expert Opinion on Biological Therapy, vol. 4, no. 10, pp. 1609-1620, 2004.

[87] X. Xu, G. Yang, H. Zhang, and G. D. Prestwich, "Evaluating dual activity LPA receptor pan-antagonist/autotaxin inhibitors as anti-cancer agents in vivo using engineered human tumors," Prostaglandins \& Other Lipid Mediators, vol. 89, no. 3-4, pp. 140146, 2009.

[88] X. Chen, X. Lin, J. Zhao et al., "A tumor-selective biotherapy with prolonged impact on established metastases based on cytokine gene-engineered MSCs," Molecular Therapy, vol. 16, no. 4, pp. 749-756, 2008.

[89] H. Xin, T. Kikuchi, S. Andarini et al., "Antitumor immune response by CX3CL1 fractalkine gene transfer depends on both NK and T cells," European Journal of Immunology, vol. 35, no. 5, pp. 1371-1380, 2005.

[90] H. Xin, M. Kanehira, H. Mizuguchi et al., "Targeted delivery of CX3CL1 to multiple lung tumors by mesenchymal stem cells," Stem Cells, vol. 25, no. 7, pp. 1618-1626, 2007.

[91] H. Xin, R. Sun, M. Kanehira et al., "Intratracheal delivery of CX3CL1-expressing mesenchymal stem cells to multiple lung tumors," Molecular Medicine, vol. 15, no. 9-10, pp. 321-327, 2009.

[92] J. Veevers-Lowe, S. G. Ball, A. Shuttleworth, and C. M. Kielty, "Mesenchymal stem cell migration is regulated by fibronectin through alpha 5 beta 1-integrin-mediated activation of PDGFRbeta and potentiation of growth factor signals," Journal of Cell Science, vol. 124, no. 8, pp. 1288-1300, 2011.

[93] S. Camorani, B. S. Hill, R. Fontanella et al., "Inhibition of bone marrow-derived mesenchymal stem cells homing towards triple-negative breast cancer microenvironment using an AntiPDGFR beta aptamer," Theranostics, vol. 7, no. 14, pp. 3595-3607, 2017.

[94] A. M. Roccaro, A. Sacco, W. G. Purschke et al., "SDF-1 inhibition targets the bone marrow niche for cancer therapy," Cell Reports, vol. 9, no. 1, pp. 118-128, 2014.

[95] S. P. Monga, "Beta-Catenin Signaling and Roles in Liver Homeostasis, Injury, and Tumorigenesis," Gastroenterology, vol. 148, no. 7, pp. 1294-1310, 2015.

[96] M. A. Chiurillo, "Role of the Wnt/beta-catenin pathway in gastric cancer: an in-depth literature review," World Journal of Experimental Medicine, vol. 5, no. 2, pp. 84-102, 2015.

[97] T. D. King, M. J. Suto, and Y. Li, “The Wnt/beta-catenin signaling pathway: a potential therapeutic target in the treatment of triple negative breast cancer," Journal of Cellular Biochemistry, vol. 113, no. 1, pp. 13-18, 2012.

[98] V. R. Dasari, K. Kaur, K. K. Velpula et al., "Upregulation of PTEN in glioma cells by cord blood mesenchymal stem cells inhibits migration via downregulation of the PI3K/Akt pathway," PLoS ONE, vol. 5, no. 4, Article ID e10350, 2010.

[99] N. Wu, Y. Zhang, H. Wang et al., "Overexpression of hepatocyte nuclear factor 4alpha in human mesenchymal stem cells suppresses hepatocellular carcinoma development through Wnt/beta-catenin signaling pathway downregulation," Cancer Biology \& Therapy, vol. 17, no. 5, pp. 558-565, 2016.

[100] H. Niess, J. C. von Einem, M. N. Thomas et al., "Treatment of advanced gastrointestinal tumors with genetically modified autologous mesenchymal stromal cells (TREAT-ME1): study protocol of a phase I/II clinical trial," BMC Cancer, vol. 15, no. 1, p. 237, 2015.

[101] M. T. Schweizer, H. Wang, T. J. Bivalacqua et al., "A phase I study to assess the safety and cancer-homing ability of allogeneic bone marrow-derived mesenchymal stem cells in men with localized prostate cancer," Stem Cells Translational Medicine, vol. 8, no. 5, pp. 441-449, 2019. 


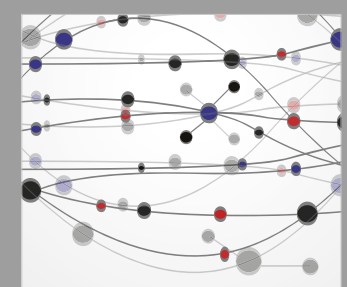

The Scientific World Journal
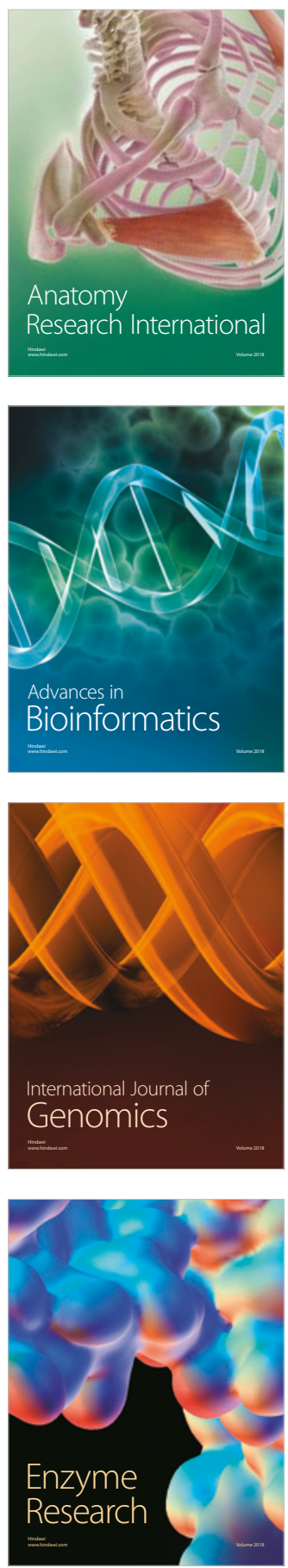
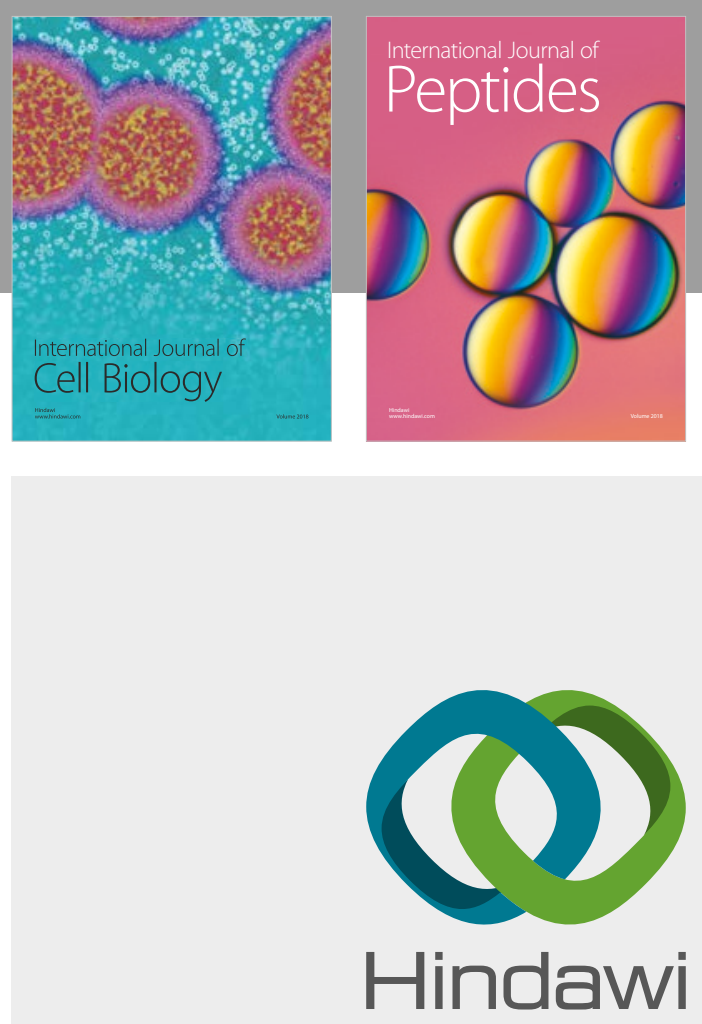

Submit your manuscripts at

www.hindawi.com
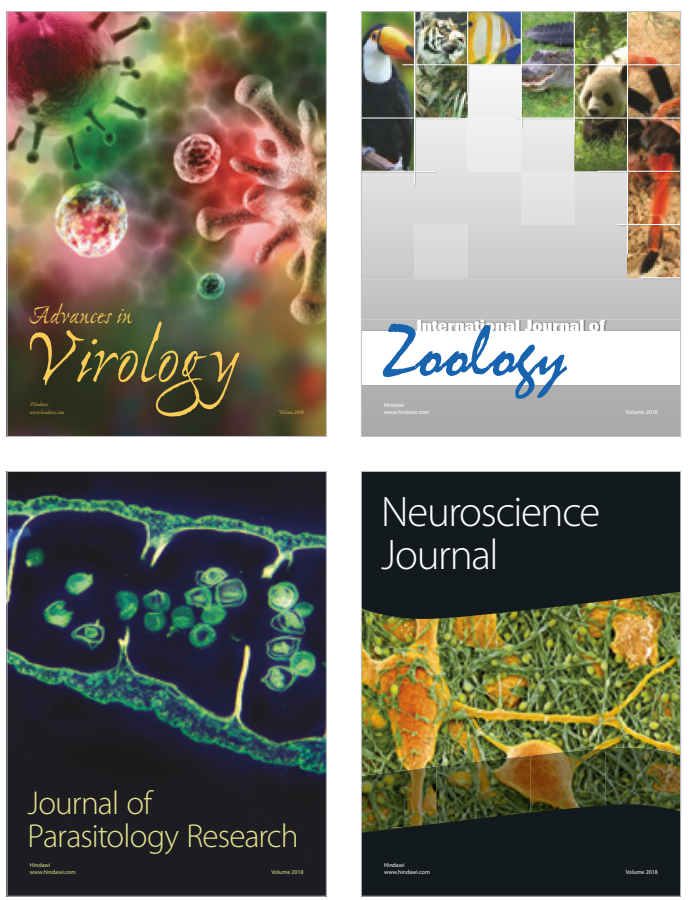
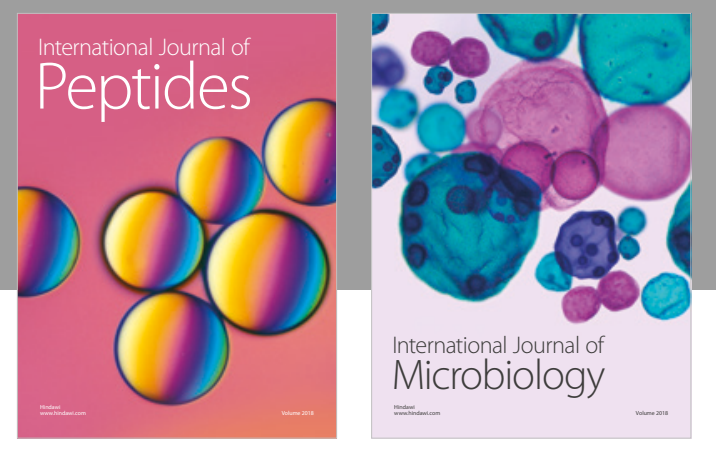

nternational Journal of Microbiology
Journal of
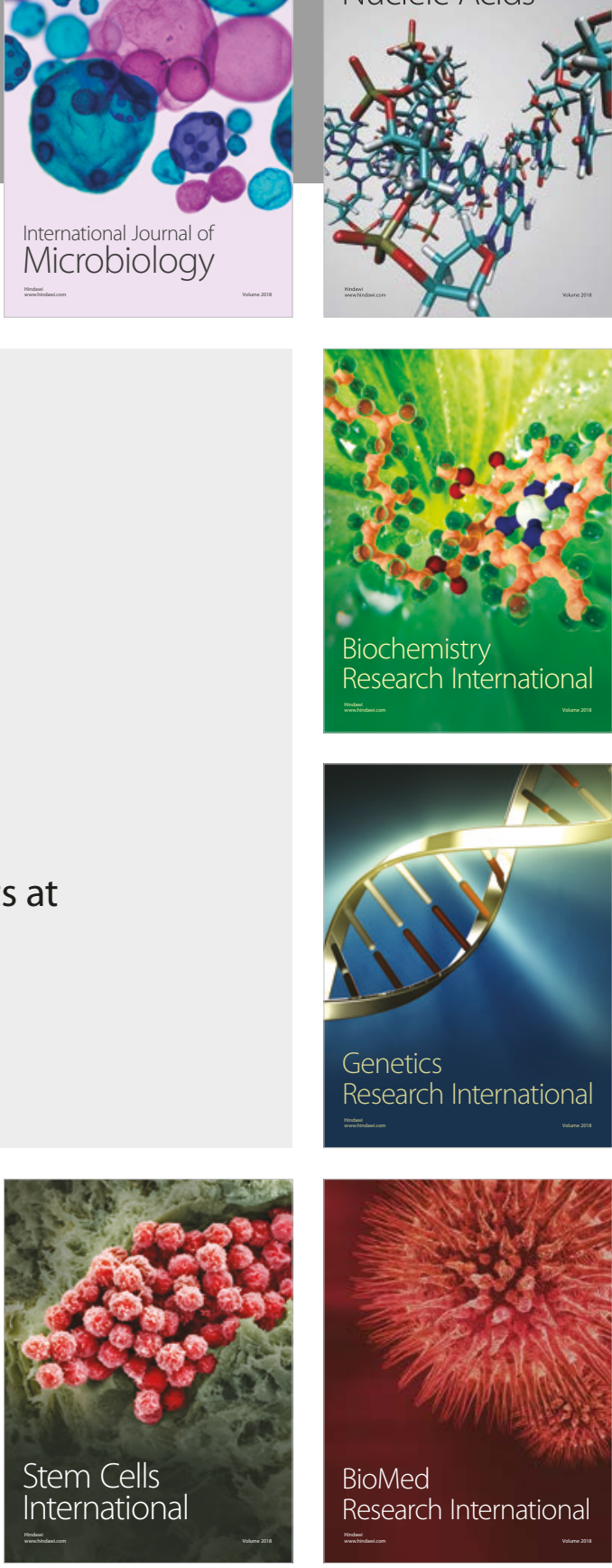
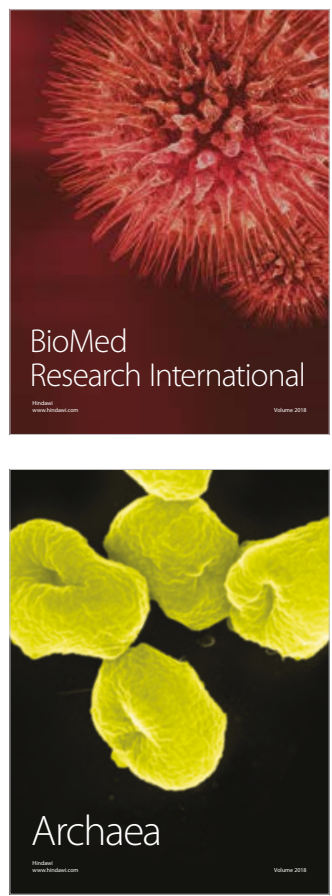